\title{
Clinical Features and Outcomes of Carcinoma of Unknown Primary Site: A Single Center Experience
}

\author{
Suzan Alhassanin ${ }^{1 *}$, Suzy Gohar ${ }^{1}$ and Shaimaa Soliman ${ }^{2}$ \\ ${ }^{1}$ Faculty of Medicine, Department of Clinical Oncology, Menoufia University, Shebin Elkom, Egypt \\ ${ }^{2}$ Faculty of Medicine, Department of Public Health and Community Medicine, Menoufia University, Shebin Elkom, Egypt
}

\begin{abstract}
Background: Carcinoma of unknown primary (CUP) is a heterogeneous entity of malignant epithelial tumors. In general, CUP follows an aggressive biological and clinical behavior. There is generally limited information regarding this issue.
\end{abstract}

Objective: To assess clinical and epidemiological features of patients diagnosed with CUP.

Patients and methods: All patients categorized as having CUP who attended the department of clinical oncology, Menoufia University from January 2013 to December 2015 were included in the study. The patients' features, investigations and clinical outcomes were collected. Also, time to progression (TTP) and overall survival (OS) were calculated.

Results: The study included 103 patients representing about $2.2 \%$ of the total number of patients visited clinical oncology department outpatients' clinic during the same period. Most of the patients were males, the mean age of the patients was 58 years, pain was the most common presenting symptom, and adenocarcinoma was the most common reported pathological subtype. Only $50.5 \%$ of the patients were fit to receive platinum combination chemotherapy. The median TTP was 2 months and the median OS was 3 months. Age, performance status and presenting symptom had statistically significant relation with TTP. While, the baseline performance status, presenting symptoms and pathological subtype had statistically significant relation with OS.

Conclusion: Carcinomas of unknown primary origin are not uncommon tumors in Clinical Oncology Department, Menoufia University with wide varieties of clinical presentations. Baseline performance status, presenting symptoms and pathological subtype had statistically significant relation with OS.

Keywords: Carcinoma of unknown primary; Diagnosis investigations; Management; Chemotherapy

\section{Introduction}

Carcinoma of unknown primary (CUP) is a common malignant syndrome representing $2-5 \%$ of all epithelial tumors [1]. This term includes all patients presenting with metastatic disease in which the primary site could not be identified, despite the use of thorough diagnostic techniques and procedures [2]. There is poor consensus on the extent of diagnostic evaluations $[3,4]$.

Cases without histological confirmation should rather be called "suspected malignancy, not otherwise specified" and a histological confirmation is now-a-days nearly always recommended - the only exception being cases where the general condition or comorbidities clearly preclude any cancer-specific intervention [5].

The standard treatment for these patients for the last years has been empiric "broad-spectrum" chemotherapy but over the last years, treatment response rates and survival of this category of patients have been improved [6]. This disease represents a health problem due to its heterogeneity, poor performance status of most of these patients, inadequate therapy and poor prognosis of most of the patients $[2,7]$.

\section{Aim of the work}

The aim of this study was to assess clinical and epidemiological characteristics of patients diagnosed with CUP at the department of Clinical oncology, Menoufia University and identify factors affecting TTP and OS in this group of patients.

\section{Patients and Methods}

This retrospective study was conducted at clinical oncology department, Faculty of Medicine, Menoufia University. After obtaining an official approval from the Ethics Committee of the Faculty, all patients files categorized as having CUP from January 2013 to December 2015 were included in the study. Patients who did not undergo biopsy or cytological assessment due to poor general condition and associated co-morbidities were also included in the study.

Patients' data including (age, gender, performance status, body mass index (BMI) [8], smoking history, family history and associated co morbidities) were collected from their files. In addition, clinical features including (presenting symptoms, involved sites, number of involved sites, baseline tumor markers, pathological subtype, pathological grade, investigations requested, type of treatment obtained and patients' fate) were also recorded.

To narrow the wide variability in presenting symptoms the authors

*Corresponding author: Suzan Alhassanin, Faculty of Medicine, Department of Clinical Oncology, Menoufia University, Shebin Elkom, Egypt, Tel: +20 482222170 ; E-mail: suzan.alhassanin@med.menofia.edu.eg

Received August 30, 2018; Accepted November 05, 2018; Published November 08, 2018

Citation: Alhassanin S, Gohar S, Soliman S (2018) Clinical Features and Outcomes of Carcinoma of Unknown Primary Site: A Single Center Experience. J Cancer Sci Ther 10: 338-344. doi: 10.4172/1948-5956.1000565

Copyright: () 2018 Alhassanin S, et al. This is an open-access article distributed under the terms of the Creative Commons Attribution License, which permits unrestricted use, distribution, and reproduction in any medium, provided the original author and source are credited. 
Citation: Alhassanin S, Gohar S, Soliman S (2018) Clinical Features and Outcomes of Carcinoma of Unknown Primary Site: A Single Center Experience. J Cancer Sci Ther 10: 338-344. doi: 10.4172/1948-5956.1000565

divided presenting symptoms into 3 major symptoms categories: pain symptoms (e.g.: headache, bony pain, abdominal pain...etc.), swelling symptoms (e.g.: lymph node swelling, abdominal swelling, bone and soft tissue swellings) and symptoms representing physiological function disturbance (e.g.: dyspnea, limb weakness, fits, fever, bleeding ...etc.).

Number of involved sites were categorized into either: single, two and $\geq 3$ involved sites. Also, organs involved were divided into 3 groups: patients with bone only metastatic disease, patients with visceral only disease (lung, liver, brain) and patients with both bone and visceral organ involvement.

Response to treatment was assessed according to revised RECIST guidelines (version 1.1) [9]. Time to progression was calculated for all patients as the length of time from the date of start of treatment until disease progression. Overall survival was calculated as the length of time from the date of start of treatment until date of patient's death. Relations between epidemiological and clinical features and both TTP and OS were estimated to assess factors affecting them. Data were analyzed by SPSS v.23 (SPSS Inc. Released 2015. IBM SPSS statistics for windows, version 23.0, Armnok, NY: IBM Corp.). Overall survival analysis and DFS were done using Kapaln-Meier statistics with log rank test to express the significance.

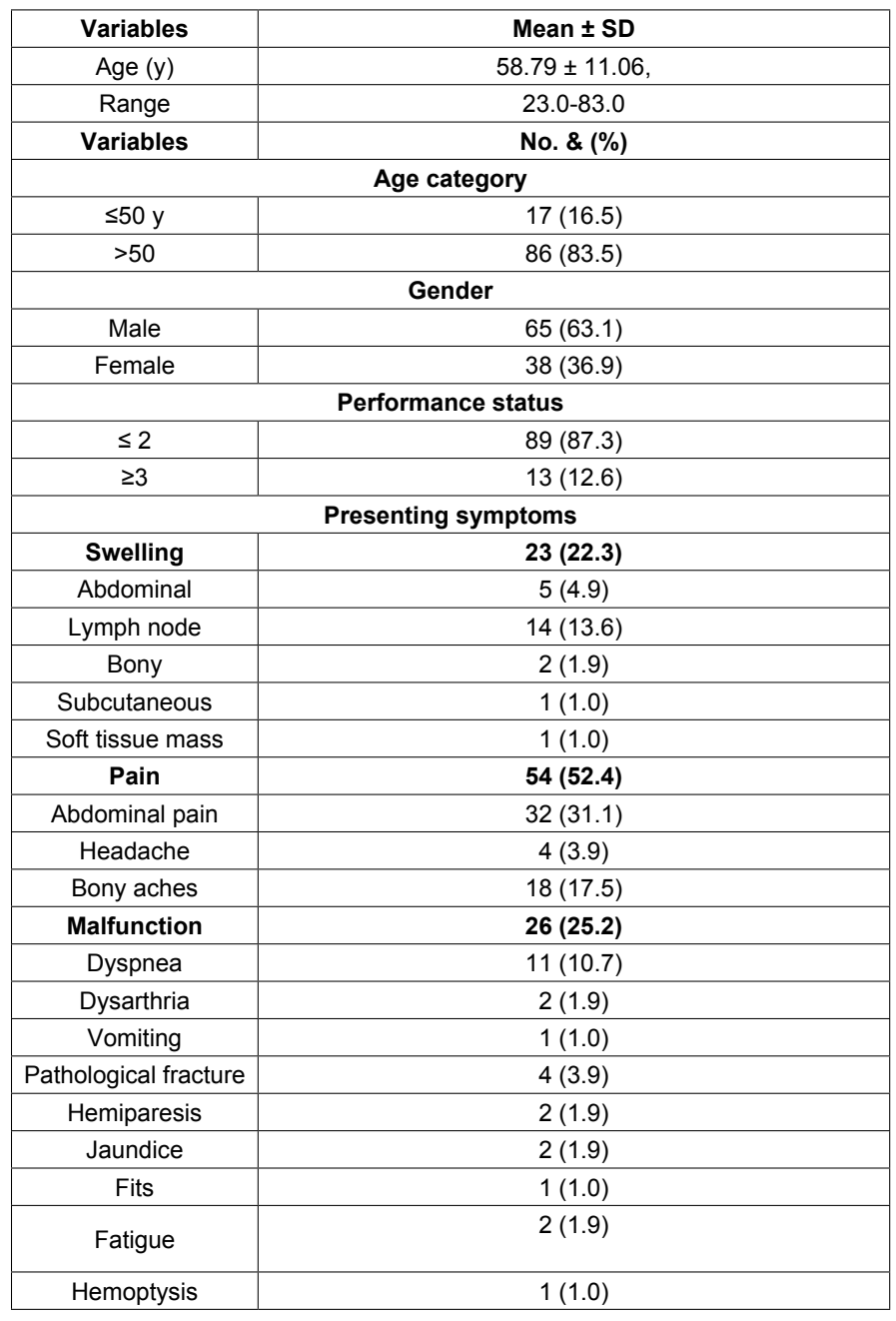

Table 1: Patients' demographic characteristics.

\begin{tabular}{|c|c|}
\hline Variables & No (\%) \\
\hline \multicolumn{2}{|l|}{ Histological diagnosis } \\
\hline Tissue Biopsy & $66(64.1)$ \\
\hline Cytology & $6(5.8)$ \\
\hline No biopsy & $31(30.1)$ \\
\hline \multicolumn{2}{|l|}{ Pathology: (For patients underwent tissue biopsy) } \\
\hline Adenocarcinoma & $37(35.9)$ \\
\hline Undifferentiated & $16(15.5)$ \\
\hline Squamous cell carcinoma & $5(4.9)$ \\
\hline Others: & $8(7.8)$ \\
\hline Neuroendocrine & $1(1.0)$ \\
\hline Small cell carcinoma & $4(3.9)$ \\
\hline Round cell tumor & $1(1.0)$ \\
\hline Anaplastic carcinoma & $2(1.9)$ \\
\hline \multicolumn{2}{|l|}{ Grade: (For patients underwent tissue biopsy) } \\
\hline 1 & $1(1.0)$ \\
\hline II & $31(30.1)$ \\
\hline III & $34(33.0)$ \\
\hline \multicolumn{2}{|l|}{ Involved Sites } \\
\hline Bone only & $11(10.7)$ \\
\hline Visceral only & $72(69.9)$ \\
\hline Bone and visceral & $20(19.4)$ \\
\hline \multicolumn{2}{|l|}{ Number of involved sites } \\
\hline Single Site & $55(53.4)$ \\
\hline Bone & 11 \\
\hline Liver & $\begin{array}{c}18 \\
5\end{array}$ \\
\hline \multicolumn{2}{|l|}{ Lung } \\
\hline Brain & 4 \\
\hline Lymph nodes & 14 \\
\hline Epigastric mass & 1 \\
\hline Malignant ascites & 1 \\
\hline Soft tissue mass & 1 \\
\hline 2 affected sites & $29(28.2)$ \\
\hline 3 or more affected sites & $19(18.5)$ \\
\hline \multicolumn{2}{|l|}{ Treatment modalities } \\
\hline BSC & $29(28.2)$ \\
\hline Palliative radiotherapy only & $19(18.4)$ \\
\hline Palliative Chemotherapy only & $49(47.6)$ \\
\hline Palliative chemo+ palliative radiotherapy & $3(2.9)$ \\
\hline Radical Radiotherapy to neck & $2(1.9)$ \\
\hline CCRTH (to neck) & $1(1.0)$ \\
\hline \multicolumn{2}{|l|}{ Variables } \\
\hline \multicolumn{2}{|l|}{ Chemotherapy } \\
\hline No chemo & $51(49.5)$ \\
\hline FOLFOX regimen & $7(6.8)$ \\
\hline Gem-Cisplatin & $12(11.7)$ \\
\hline Gem-carboplatin & $11(10.7)$ \\
\hline Taxol-carboplatin & $22(21.4)$ \\
\hline \multicolumn{2}{|l|}{ Cause of death } \\
\hline Liver failure & $36(35.0)$ \\
\hline Respiratory causes & $20(19.6)$ \\
\hline Heart failure & $2(1.9)$ \\
\hline Septic shock & $9(7.8)$ \\
\hline Hypovolemic shock and bleeding & $3(2.9)$ \\
\hline Status epileptics and coma due brain involvement & $7(6.8)$ \\
\hline Renal failure & $3(1.9)$ \\
\hline Intestinal obstruction & $4(2.9)$ \\
\hline
\end{tabular}

Table 2: Disease characteristics. 
Citation: Alhassanin S, Gohar S, Soliman S (2018) Clinical Features and Outcomes of Carcinoma of Unknown Primary Site: A Single Center Experience. J Cancer Sci Ther 10: 338-344. doi: 10.4172/1948-5956.1000565

\begin{tabular}{|c|c|c|c|c|c|c|c|}
\hline \multirow{3}{*}{ Items } & \multicolumn{3}{|c|}{ Mean } & \multicolumn{3}{|c|}{ Median } & \multirow{3}{*}{$\begin{array}{c}\text { Log rank } \\
\text { p-value }\end{array}$} \\
\hline & \multirow{2}{*}{ Estimate } & \multicolumn{2}{|c|}{$95 \% \mathrm{Cl}$} & \multirow{2}{*}{ Estimate } & \multicolumn{2}{|c|}{$95 \% \mathrm{Cl}$} & \\
\hline & & Lower & Upper & & Lower & Upper & \\
\hline \multicolumn{8}{|c|}{ Age } \\
\hline$\leq 50$ & 6.78 & 3.46 & 10.09 & 4.0 & 1.38 & 6.61 & 5.88 \\
\hline$>50$ & 3.49 & 2.65 & 4.33 & 2.0 & 1.75 & 2.24 & 0.012 \\
\hline Overall & 4.07 & 3.12 & 5.03 & 2.0 & 1.55 & 2.44 & -- \\
\hline \multicolumn{8}{|c|}{ Gender } \\
\hline Male & 4.08 & \multirow{2}{*}{$\begin{array}{l}2.82 \\
2.64 \\
\end{array}$} & \multirow{2}{*}{$\begin{array}{l}5.35 \\
5.43 \\
\end{array}$} & 2.0 & 1.51 & 2.48 & 0.005 \\
\hline Female & 4.03 & & & 2.0 & 0.99 & 3.00 & 0.944 \\
\hline Overall & 3.07 & 3.12 & 5.03 & 2.0 & 1.55 & 2.44 & -- \\
\hline \multicolumn{8}{|c|}{ Performance status } \\
\hline$\leq 2$ & 4.42 & 3.36 & 5.48 & 3.0 & 2.54 & 3.45 & 14.35 \\
\hline$>2$ & 1.45 & 1.07 & 1.83 & 1.5 & 1.11 & 1.88 & $<0.001$ \\
\hline Overall & 4.07 & 3.12 & 5.03 & 2.0 & 1.55 & 2.44 & -- \\
\hline \multicolumn{8}{|c|}{ Presenting symptoms } \\
\hline Pain & 3.48 & 2.62 & 4.34 & 2.0 & 1.47 & 2.53 & \\
\hline Functional dis. & 2.42 & 1.78 & 3.16 & 2.0 & 1.30 & 2.69 & 12.44 \\
\hline Swelling & 7.47 & 4.16 & 10.78 & 4.0 & 0.63 & 7.36 & 0.002 \\
\hline Overall & 4.07 & 3.12 & 5.03 & 2.0 & 1.55 & 2.44 & -- \\
\hline \multicolumn{8}{|c|}{ Pathology } \\
\hline Adenocarcinoma & 4.43 & 2.98 & 5.87 & 3.0 & 1.89 & 4.10 & -- \\
\hline SCC & 10.20 & 3.89 & 16.50 & 11.0 & 0.0 & 28.17 & 7.18 \\
\hline Undifferentiated. & 4.15 & 2.55 & 5.76 & 3.0 & 1.73 & 4.26 & 0.061 \\
\hline Others & 2.50 & 1.57 & 3.42 & 3.0 & 1.80 & 4.20 & -- \\
\hline Overall & 4.61 & 3.47 & 5.75 & 3.0 & 2.60 & 3.39 & -- \\
\hline \multicolumn{8}{|c|}{ Grade } \\
\hline 1 & 2.00 & 2.0 & 2.0 & 2.0 & - & - & -- \\
\hline II & 5.04 & 3.23 & 6.86 & 4.0 & 3.133 & 4.87 & 1.00 \\
\hline III & 4.25 & 2.82 & 5.68 & 3.0 & 2.26 & 3.73 & 0.601 \\
\hline Overall & 4.61 & 3.48 & 5.75 & 3.0 & 2.60 & 3.39 & -- \\
\hline \multicolumn{8}{|c|}{ Site } \\
\hline Bone only & 2.31 & 1.34 & 3.29 & 2.0 & 1.27 & 2.74 & 2.91 \\
\hline Visceral & 4.53 & 3.25 & 5.82 & 2.50 & 1.98 & 3.01 & 0.239 \\
\hline Bone and visceral & 3.55 & 1.77 & 5.33 & 3.0 & 1.94 & 4.05 & -- \\
\hline Overall & 4.07 & 3.12 & 5.03 & 2.0 & 1.55 & 2.44 & -- \\
\hline \multicolumn{8}{|c|}{ No. of sites } \\
\hline One & 4.63 & 3.03 & 6.23 & 2.5 & 1.81 & 3.18 & 0.94 \\
\hline Two & 3.55 & 2.59 & 4.51 & 3.0 & 1.92 & 4.07 & 0.621 \\
\hline Three & 3.30 & 1.40 & 5.20 & 2.0 & 1.75 & 2.24 & -- \\
\hline Overall & 4.06 & 3.11 & 5.02 & 2.0 & 1.55 & 2.44 & -- \\
\hline \multicolumn{8}{|c|}{ Treatment modalities } \\
\hline BSC & 1.49 & 1.06 & 1.91 & 1.0 & 0.85 & 1.14 & 51.14 \\
\hline Palliative radiotherapy & 2.0 & 1.47 & 2.54 & 2.0 & 1.80 & 2.19 & $<0.001$ \\
\hline Palliative Chemotherapy & 5.04 & 3.92 & 6.16 & 4.0 & 3.48 & 4.51 & -- \\
\hline Palliative chemo+radiotherapy & 6.0 & 0.81 & 11.18 & 5.0 & 0.19 & 9.80 & -- \\
\hline Overall & 3.47 & 2.79 & 4.16 & 2.0 & 1.56 & 2.43 & -- \\
\hline & & Chemot & regimer & & & & \\
\hline FOLFOX & 5.0 & 2.81 & 7.18 & 5.0 & 2.43 & 6.56 & 4.79 \\
\hline Gem-CIS & 3.91 & 2.42 & 5.41 & 3.0 & 2.46 & 3.53 & 0.180 \\
\hline Gem-carbo & 3.72 & 2.40 & 5.05 & 3.0 & - & - & -- \\
\hline Taxol-carbo & 6.27 & 4.15 & 8.39 & 4.0 & 2.85 & 5.14 & -- \\
\hline Overall & 5.01 & 3.94 & 6.09 & 4.0 & 3.45 & 4.54 & -- \\
\hline
\end{tabular}

Table 3: Relation between time to progression and patients/disease features.

\section{Results}

The study included 103 patients who were diagnosed to have CUP from January 2013 to December 2015 representing about $2.2 \%$ of the total number of the patients (4578 patients) who visited clinical oncology department outpatients' clinic during the same period.

\section{Patient characteristics}

Age of the patients ranged from 23.0 to 83 years (mean age of 58.79-years-old) with most of the patients above 50 years ( $83.5 \%)$. Sixtyfive patients were males (63.1\%). Never smokers represented $59.2 \%$ of the patients, only 9 patients $(8.7 \%)$ had family history of malignant 
Citation: Alhassanin S, Gohar S, Soliman S (2018) Clinical Features and Outcomes of Carcinoma of Unknown Primary Site: A Single Center Experience. J Cancer Sci Ther 10: 338-344. doi: 10.4172/1948-5956.1000565

\begin{tabular}{|c|c|c|c|c|c|c|c|}
\hline \multirow{3}{*}{ Variable (no. of events/ total) } & \multicolumn{3}{|c|}{ Mean } & \multicolumn{3}{|c|}{ Median } & \multirow{3}{*}{$\begin{array}{c}\text { Log rank } \\
\text { p-value }\end{array}$} \\
\hline & \multirow{2}{*}{ Estimate } & \multicolumn{2}{|c|}{$95 \% \mathrm{Cl}$} & \multirow{2}{*}{ Estimate } & \multicolumn{2}{|c|}{$95 \% \mathrm{CI}$} & \\
\hline & & Lower & Upper & & Lower & Upper & \\
\hline \multicolumn{8}{|c|}{ Age } \\
\hline$\leq 50(14 / 17)$ & 8.14 & 4.72 & 11.55 & 6.0 & 3.75 & 8.24 & \multirow[t]{2}{*}{0.154} \\
\hline$>50(70 / 84)$ & 6.17 & 4.35 & 7.98 & 2.50 & 1.94 & 3.05 & \\
\hline \multicolumn{8}{|c|}{ Gender } \\
\hline Male $(51 / 63)$ & 6.01 & 4.22 & 7.79 & 3.0 & 2.07 & 3.93 & \multirow{2}{*}{0.857} \\
\hline Female $(33 / 38)$ & 6.76 & 4.08 & 9.45 & 3.0 & 1.70 & 4.29 & \\
\hline \multicolumn{8}{|c|}{ Performance status } \\
\hline$\leq 2(73 / 88)$ & 6.98 & 5.20 & 8.77 & 3.5 & 2.79 & 4.20 & \multirow{2}{*}{0.002} \\
\hline$>2(11 / 13)$ & 1.80 & 1.24 & 2.36 & 1.5 & - & - & \\
\hline \multicolumn{8}{|c|}{ Presenting symptoms $^{1}$} \\
\hline Pain $(45 / 51)$ & 5.11 & 3.78 & 6.45 & 3.0 & 2.28 & 3.71 & \multirow{3}{*}{0.045} \\
\hline Functional dis. (24/29) & 4.37 & 2.38 & 6.37 & 2.0 & 1.57 & 2.42 & \\
\hline Swelling (15/21) & 10.57 & 5.94 & 15.19 & 6.0 & 0.54 & 11.45 & \\
\hline \multicolumn{8}{|c|}{ Pathology ${ }^{2}$} \\
\hline Adenocarcinoma $(29 / 36)$ & 8.22 & 5.18 & 11.26 & 4.0 & 1.79 & 6.20 & \multirow{4}{*}{0.041} \\
\hline $\operatorname{SCC}(2 / 5)$ & 13.26 & 2.95 & 19.05 & - & - & - & \\
\hline Undifferentiated (15/16) & 5.68 & 1.25 & 8.14 & 3.0 & 0.0 & 6.92 & \\
\hline Others $(8 / 8)$ & 2.90 & 0.42 & 3.74 & 3.0 & 1.65 & 4.34 & \\
\hline \multicolumn{8}{|c|}{ Grade } \\
\hline$I(1 / 1)$ & 2.00 & 2.0 & 2.0 & 2.0 & - & - & \\
\hline II $(23 / 31)$ & 9.49 & 5.88 & 13.15 & 6.0 & 3.78 & 8.21 & \multirow{2}{*}{0.175} \\
\hline III $(30 / 33)$ & 5.69 & 3.78 & 7.59 & 3.0 & 1.59 & 4.40 & \\
\hline \multicolumn{8}{|c|}{ Site } \\
\hline Bone only $(8 / 10)$ & 2.75 & 1.58 & 3.91 & 2.0 & 1.29 & 2.71 & \multirow{3}{*}{0.402} \\
\hline Visceral (60/72) & 6.55 & 4.84 & 8.27 & 3.0 & 2.24 & 3.75 & \\
\hline Bone and visceral $(16 / 19)$ & 5.50 & 2.19 & 8.82 & 3.0 & 0.86 & 5.13 & \\
\hline \multicolumn{8}{|c|}{ No. of sites } \\
\hline One $(46 / 54)$ & 5.99 & 4.07 & 7.91 & 3.0 & 1.80 & 4.19 & \\
\hline Two $(23 / 28)$ & 6.38 & 4.31 & 8.46 & 3.50 & 1.30 & 5.70 & 0218 \\
\hline Three (14/18) & 5.71 & 1.30 & 10.13 & 2.50 & 1.21 & 3.78 & 0.218 \\
\hline More than three $(1 / 1)$ & 1.00 & 1.00 & 1.00 & - & - & - & \\
\hline & & ent moc & & & & & \\
\hline BSC $(26 / 28)$ & 1.63 & 1.14 & 2.12 & 1.0 & 0.92 & 1.07 & \\
\hline Palliative radiotherapy $(14 / 18)$ & 2.67 & 1.90 & 3.43 & 2.0 & 1.74 & 2.25 & 促 01 \\
\hline Chemotherapy (40/48) & 8.41 & 6.16 & 10.66 & 5.0 & 3.80 & 6.19 & $<0.001$ \\
\hline Palliative chemo and radiotherapy $(3 / 3)$ & 7.0 & 0.69 & 13.30 & 6.0 & 0.00 & 12.40 & \\
\hline & $\mathrm{Ch}$ & herapy & nen $^{4}$ & & & & \\
\hline FOLFOX (7/7) & 6.71 & 3.79 & 9.63 & 7.0 & 4.65 & 9.34 & \\
\hline Gem-CIS (11/12) & 5.95 & 2.93 & 8.97 & 4.0 & 3.26 & 4.73 & 0050 \\
\hline Gem-carbo (11/11) & 5.18 & 2.92 & 7.44 & 4.0 & 3.47 & 4.52 & 0.050 \\
\hline Taxol-carbo (15/22) & 11.89 & 7.57 & 16.22 & 8.0 & 3.92 & 12.07 & \\
\hline $\begin{array}{l}{ }^{1} \text { Swelling }>\text { pain }(0.04) \text {, > Function dist }(0.04) \\
{ }^{2} \text { Pathology: other <adeno }(0.04),<\text { SCC }(0.02) \\
{ }^{3} \text { BSC < palliative radio }(0.003) \text { chemo }(p<0.001) \\
\text { C } \mathrm{T} \text { axol-carbo }>\text { Gem-CIS }(0.04),>\text { Gem-carbo }(0.0\end{array}$ & adio+che & & & & & & \\
\hline
\end{tabular}

Table 4: Survival analysis in relation to patients \& disease features.

tumors ( 3 with breast cancer, 2 with colon cancer, 1 with each of the followings: hepatocellular carcinoma, bronchogenic carcinoma and ovarian carcinoma).

Eighty-seven percent had performance status of $\leq 2$ at presentation (89 patients). The most common presenting symptom was pain in 54 patients $(52.4 \%)$ mainly abdominal pain; followed by functional disturbances (25.2\%) and finally swellings (22.3\%) mainly lymph node swellings (Table 1).

\section{Investigations requested}

All patients underwent computed tomography scan of the chest, abdomen and pelvis, bone scan, mammography in females, complete blood count, complete liver and kidney functions as baseline evaluation. Pan-endoscopy with random biopsies requested in 5 patients presented with neck nodes proved to be squamous cell carcinoma (SCC). Twelve patients out of the 18 patients presented with isolated liver metastases underwent upper and lower GIT endoscopy which was inconclusive. Complete tumor markers panel were not requested in all patients 
as there is no minimum limit for laboratory investigations needed to diagnose CUP. CEA, CA19.9 and AFP were the most frequently requested markers with normal results in most of patients.

\section{Pathological diagnosis}

Among the 72 patients with available pathological diagnosis, adenocarcinoma (AC) was reported in 37 patients followed by undifferentiated type tumors in 16 patients. Squamous cell carcinoma subtype was seen in 5 patients with cervical lymph node presentation in 3 of them. Majority of the patients had grade II and III tumors. Thirty-one patients could not undergo tissue biopsy or FNAC due to associated co-morbidities. Fifty-three percent had only one involved metastatic site at presentation with the liver being the most common single involved site followed by lymph nodes then bone (Table 2).

Immuno-phenotyping results were reported in 47 out of 66 patients (due to poor specimen quality in the rest of cases) with the most commonly requested panel: leucocytic common antigen (LCA), cytokeratin (CK) 7 and 20, thyroid transcription factors (TTF1), Hepapar, CA 125, estrogen receptors, progesterone receptors, S100 and vimentin. Immunophenotyping results were generally good negative i.e.: excluding certain site but not conclusive regarding the certain origin of the tumor.

\section{Treatment}

Twenty-eight percent of the CUP patients received only best supportive care (BSC) due to poor performance status and/or organ dysfunction. Among the active treatment given, chemotherapy regimens prescribed were platinum-based combinations with TaxolCarboplatin the most common regimen representing $21.4 \%$, then Gemcitabine Platinum combination in $22.4 \%$ and finally FOLFOX regimen $6.8 \%$ (Table 2 ).

\section{Factors affecting survival}

Median TTP was 2 months and median OS was 3 months (Figures 1 and 2) reflecting the poor survival of our CUP patients' category. We found no statistically significant relations between TTP and gender, smoking history, positive family history of cancer or BMI. However, patients aged less than 50 years and the good performance presentations had statistically significant longer TTP. The pathological subtype was

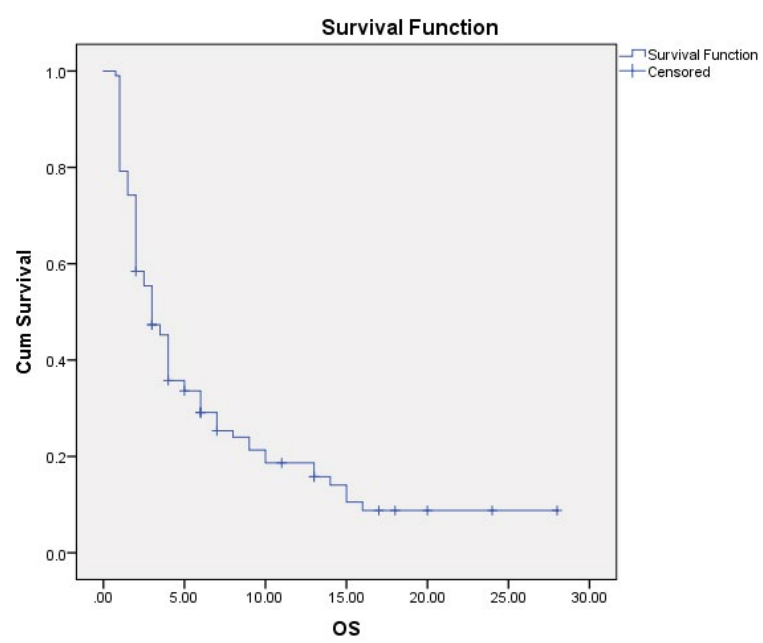

Figure 1: Kaplan Meier curve showing overall survival time.

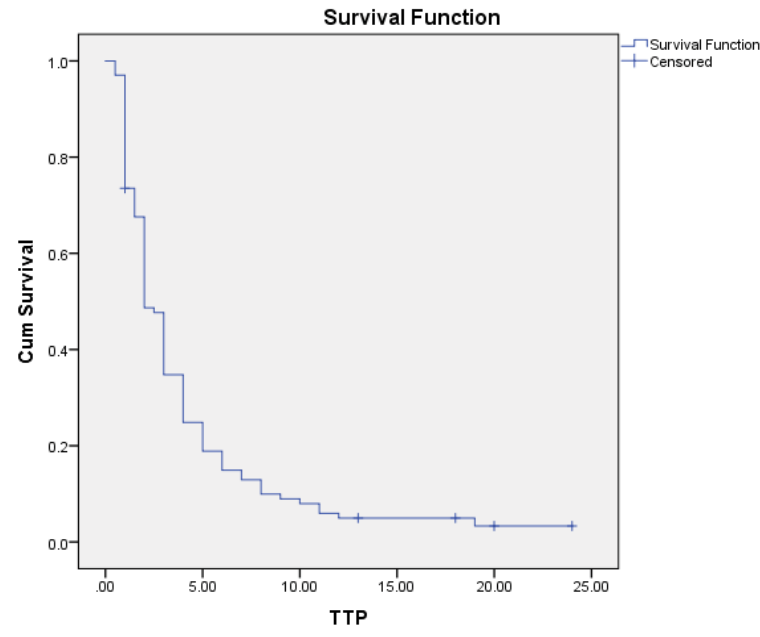

Figure 2: Kaplan Meier curve showing time to progression.

significantly related to TTP. Patients with SCC had the highest mean of TTP (13.26 weeks), with less than $50 \%$ of those patients showed progression of their disease (there was no median TTP) (Table 3).

Another finding at our study is that patients who generally presented with swelling experienced statistically significant longer TTP compared to others.

Again, performance status, type of treatment modality and pathological subtype were the only factors that had statistically significant relation with median OS (Table 4).

\section{Discussion}

Cancer of unknown primary site represents many types of cancers rather than a single disease entity [6]. In the current study CUP represented about $2.2 \%$ of the whole patients who attended our department clinic. This percent is lower than that reported by Shaw who reported that CUP represents $3.7 \%$ of all cancer referral in their center in United Kingdom [10].

The median TTP for our patients was 2 months and median OS was 3 months indicating very poor prognosis of this patients group. Shaw reported that the median OS of their patients was 4 months. However, it was 6.2 months in a study done by Chen. This slight difference could be explained by differences in treatment regimens and involved sites $[10,11]$.

The mean patients age at diagnosis was $58.79 \pm 11.06$ years which is a little bit younger than that recorded by Mahmood ( $56 \pm 16$ years). Also, this age range is 10 years younger than that reported by Shaw who found that the median age in their study was 68 years $[10,12]$.

In our study age had statistically significant relation with TTP, where patients aged $\leq 50$ years had longer TTP. Also, patients aged $\leq 50$ years had better survival (although not statistically significant). Compared to others this could be explained by the fact that younger patients had better performance status and lesser co-morbidities and therefore were able to receive active treatment.

Sixty-five patients were males (63.1\%) and 38 (36.9) patients were females with male to female ratio:1.7: 1 these values are similar to results presented by Mahmood who reported that males represented 
$55 \%$ of the patients and females represented $45 \%$ with male to female ratio of 1.2:1. On the contrary, Shaw reported that $52 \%$ of their patients were females. There was no statistically significant relation between gender and survival however he found that female gender was a good prognostic factor $[10,12]$

In the current study $12.7 \%$ of the patients had ECOG performance status $\geq 3$. While Chen found that $52 \%$ of the patients in their study had performance status $\geq 2$. Performance status had statistically significant relation with both TTP and OS. In agreement with both Shaw, and Chen who found that performance status $\geq 2$ was a statistically significant independent prognostic factor for shorter survival $[10,11]$. Again, this could be explained by the fact that patients with good performance status were able to receive active treatment.

The authors included 72 patients representing (69.9\%) with confirmed pathological diagnosis (66 patients could undergo tissue biopsy, while only 6 patients were diagnosed by FNAC) while 31 (30.1\%) patients could not undergo tissue biopsy or FNAC due to associated co-morbidities namely advanced liver cell failure or disseminated brain lesions. The same was a difficulty also found in CUP patients at both Mahmood and Shaw studies [10,11].

Adenocarcinoma was the most common pathological subtype reported, followed by undifferentiated carcinoma then SCC which is like what was reported by Mahmood, Kim and Hemminki [12-14]. However, Chen [11] reported that unclassifiable carcinoma followed by adenocarcinoma were the most common subtypes. Patients with SCC pathology had best survival followed by adenocarcinoma, in agreement with that of Kim [13].

Chen found that lymph nodes, lungs, liver, and bones were the most frequently involved organs. Shaw reported that liver and multiple sites, and then bone and brain were the most frequently involved sites $[10,11]$. Both were different from our findings.

Patients who presented with $\geq 3$ involved sites had statistically nonsignificant poor survival. While Hemminki [15] who studied patients with extra-nodal disease and adenocarcinoma pathology found that patients with liver involvement had least survival. Also, Chen [11] reported that multiple $(\geq 2)$ metastatic sites were independent factors of poor prognosis.

Another important finding is that no statistically significant relation existed between tumor markers and both TTP and OS. On the contrary, Milović [16] found that patients with elevated CEA levels had poor survival compared by others.

Regarding treatment modalities Shaw (10), reported in his study that $(28.0 \%)$ of patients received radiotherapy, $(18.0 \%)$ received chemotherapy and $(35.0 \%)$ received supportive care alone. While in our study we found that $23.2 \%$ of the patients received radiotherapy either as single modality, in association with chemotherapy or on radical base. And $50.5 \%$ received chemotherapy, while $28.2 \%$ of the patients were kept under best supportive care.

Chemotherapy prescribed either alone or in combination with radical or palliative radiotherapy had statistically significant longer TTP and better survival compared to patients who received palliative radiotherapy alone or BSC. These finding are consistent with that reported by Chen and Shaw $[10,11]$. Patients presented with cervical lymph node swelling and treated as SCC of head and neck showed the longest TTP and survival.
The median TTP of patients in chemotherapy only group was 4 months and median survival was 5 months this survival time was shorter than the 9 months reported by Chen [11].

The most popular regimen prescribed at our department was Taxol-Carboplatin combination. Due to its wide range of effectiveness and accepted toxicity profile this may explain that this regimen was associated with the best survival. Patients who received FOLFOX regimens had the longest TTP and good survival compared to others as these patients were treated as possible colorectal origin tumor (most of them had cytokeratin 20 positive pathologies), while patients with the least survival and TTP who received gemcitabine based combinations were treated as primary pancreatic, gall bladder or lung origin (most of them had positive cytokeratin 7 pathologies) and these tumor types are generally carrying worse prognosis. In Chen study the cisplatin containing regimen was the most popular, then 5FU containing regimen then Taxane based regimens, this difference in treatment regiments may be related to institutional variations and the absence of treatment guidelines [11].

\section{Conclusion}

Carcinoma of unknown primary origin is a poor prognostic disease at Menoufia University clinical oncology department. Patients presented with wide varieties of presenting symptoms and involved sites. Age, performance status, presenting symptom, baseline performance status and pathological subtype had statistically significant effect on survival. Treatment modalities were the most important factor that affected patients' outcomes and had statistically significant relation with both TTP and overall survival. There is an urgent need for local and international consensus guidelines to help establishing the appropriate management of such patient group.

\section{References}

1. Pavlidis N, Khaled H, Gaafar R (2015) A mini review on cancer of unknown primary site: A clinical puzzle for the oncologists. J Adv Res 6: 375-382.

2. Pejcic I, Vrbic S, Todorovic M, Petkovic I, Balic M, et al. (2014) Cancer of unknown primary site syndrome-cup syndrome - diagnostic and therapeutical dillemas. Acta Facultatis Medicae Naissens 31: 87-94.

3. Stella GM, Senetta R, Cassenti A, Ronco M, Cassoni P (2012) Cancers of unknown primary origin: current perspectives and future therapeutic strategies. J Transl Med 10:12.

4. Pavlidis N, Pentheroudakis G (2012) Cancer of unknown primary site. Lancet 379: $1428-1435$

5. Loffler $\mathrm{H}$, Krämer A (2016) Introduction. In: Kramer A, Loffler H Cancer of Unknown Primary. Springer International Publishing Switzerland pp. 1-5.

6. Greco FA (2012) Cancer of unknown primary site: Evolving understanding and management of patients. Clin Adv Hematol Oncol 10: 518-524.

7. Briasoulis E, Tolis C, Bergh J, Pavlidis N (2005) ESMO Guidelines Task Force. ESMO minimum clinical recommendations for diagnosis, treatment and followup of cancers of unknown primary site (CUP). Ann Oncol 16: i75-i76.

8. World Health Organization. Global database on body mass index. Available from: [http://www.who.int/bmi/index. Jsp- intro Page=intro 3.html] Accessed on 5 November 2018.

9. Oken MM, Creech RH, Tormey DC, Horton J, Davis TE, et al. (1982) Toxicity and response criteria of the eastern cooperative oncology group. Am J Clin Oncol 5: 649-655.

10. Shaw PH, Adams R, Jordan C, Crosby TD (2007) A clinical review of the investigation and management of carcinoma of unknown primary in a single cancer network. Clin Oncol (R Coll Radiol)19: 87-95.

11. Chen KW, Liu CJ, Lu HJ, Tzeng CH, Liu JH, et al. (2012) Evaluation of prognostic factors and the role of chemotherapy in unfavorable carcinoma of unknown primary site: A 10-year cohort study. BMC Res Notes 5: 70. 
Citation: Alhassanin S, Gohar S, Soliman S (2018) Clinical Features and Outcomes of Carcinoma of Unknown Primary Site: A Single Center Experience. J Cancer Sci Ther 10: 338-344. doi: 10.4172/1948-5956.1000565

12. Mahmood RI, Aldehaim M, Hussain F, Elhassan TA, Khan ZA, et al. (2016) Carcinoma of unknown primary: 35 years of a Single Institution's Experience. Cancer Transl Med 2: 113-118.

13. Kim CS, Hannouf MB, Sarma S, Rodrigues GB, Rogan PK, et al. (2015) Identification and survival outcomes of a cohort of patients with cancer of unknown primary in Ontario, Canada. Acta Oncol 54: 1781-1787.

14. Hemminki K, Bevier M, Hemminki A, Sundquist J (2012) Survival in cancer of unknown primary site: population based analysis by site and histology. Ann Oncol 23: 1854-1863.

15. Hemminki K, Riihimäki M, Sundquist K, Hemminki A (2013) Site-specific survival rates for cancer of unknown primary according to location of metastases. Int J Cancer 133: 182-189.

16. Milovic M, Popov I, Jelic S (2002) Tumor markers in metastatic disease from cancer of unknown primary origin. Med Sci Monit 8: MT25-30. 